\title{
Robustness of a Simple Rule for the Social Cost of Carbon
}

\author{
Armon Rezai \\ Frederick van der Ploeg
}

CESIFO WORKING PAPER NO. 4703

CATEGORY 10: ENERGY AND CLIMATE ECONOMICS

ORIGINAL VERSION: MARCH 2014

THIS VERSION: APRIL 2015

An electronic version of the paper may be downloaded

- from the SSRN website:

- from the RePEc website:

- from the CESifo website:

WWw.SSRN.com

www.RePEc.org

www.CESifo-group.org/wp

\section{CESifo}




\title{
Robustness of a Simple Rule for the Social Cost of Carbon
}

\begin{abstract}
The optimal social cost of carbon is in general equilibrium proportional to GDP if utility is logarithmic, production is Cobb-Douglas, depreciation is $100 \%$ every period, climate damages as fraction of production decline exponentially with the stock of atmospheric carbon, and fossil fuel extraction does not require capital. The time profile and size of the optimal carbon tax corresponding to this simple rule are not robust to more convex climate damages, smaller elasticities of factor substitution and non-unitary coefficients of relative intergenerational inequality aversion. The optimal timing of energy transitions and the amount of fossil fuel reserves to be locked up in the earth are also not accurately predicted by this framework. Still, in terms of welfare and global warming the simple rule for the optimal social cost of carbon manages to get quite close to the first best.
\end{abstract}

JEL-Code: H210, Q510, Q540.

Keywords: social cost of carbon, Ramsey growth, climate damages, energy transitions, stranded fossil, fuel assets, robustness.

\author{
Armon Rezai* \\ Department of Socioeconomics \\ Welthandelsplatz 1 / Vienna / Austria \\ \& IIASA / 2361 Laxenburg / Austria \\ Armon.Rezai@wu.ac.at
}

\author{
Frederick van der Ploeg** \\ Department of Economics \\ University of Oxford \\ Manor Road Building \\ UK - Oxford OX1 3UQ \\ rick.vanderploeg@economics.ox.ac.uk
}

February 2014, revised March 2015

Research highlights:

- The social cost of carbon (SCC) is a hump-shaped function of world GDP.

- The SCC increases rapidly and peaks well into the post-carbon era.

- A proportional-to-GDP carbon tax rule approximates the first-best welfare closely.

- Such a rule errs in the amount of fossil fuel reserves to be locked-up in situ

*corresponding author/Support from the OeNB Anniversary Fund (grant no. 15330) is gratefully acknowledged. **Support from ERC Advanced Grant 'Political Economy of Green Paradoxes' (FP7-IDEAS-ERC Grant No. 269788) and the BP funded Oxford Centre for the Analysis of Resource Rich Economies is gratefully acknowledged. 


\section{Introduction}

A tractable model of the optimal carbon tax has been put forward by Golosov et al. (2014) based on a decadal Ramsey growth model and been extended by Hassler and Krusell (2012), Gerlagh and Liski (2012) and Iverson (2013). This model makes the following bold assumptions: logarithmic utility, Cobb-Douglas production, $100 \%$ depreciation of physical capital each period, relatively gradual marginal damages, and zero capital intensity of fossil fuel extraction. The assumption of full depreciation necessitates a coarse calibration grid, but with them it can be shown analytically that the social cost of carbon (SCC) is proportional to current GDP and independent of technology. We evaluate the robustness of this simple formula in a more general Ramsey growth model which relaxes these bold assumptions by introducing CES utility to allow for non-unitary coefficients of relative intergenerational inequality aversion, CES production with a much lower elasticity of factor substitution as suggested by Hassler et al. (2012), partial depreciation of physical capital and more convex climate damages as suggested by Weitzman (2010). Furthermore, with our integrated assessment model we want to speak to the issue of the optimal amount of fossil fuel to lock up in the earth and thus limit the cumulative amount of carbon emissions as this has been argued by climate scientists to be a crucial element of climate policy (e.g., McGlade and Ekins, 2015). To capture this, we allow in contrast to Golosov et al. (2014) for extraction costs that rise as fossil fuel reserves diminish and less accessible and more costly fields have to be explored and we also allow for a renewable backstop that is a perfect substitute for fossil fuel. These extensions allow us to have endogenous energy transition times for the switch to the carbon-free era and to determine the optimal and business-as-usual level of untapped fossil fuel reserves.

\section{Ramsey growth and energy transitions}

Let social welfare be utilitarian, with per capita utility $U$ depending on per capita consumption $C_{t} / L_{t}$, where $L_{t}$ is the exogenous population size and $\rho$ the rate of time preference:

$$
\mathrm{E}_{0}\left[\sum_{t=0}^{\infty}\left(\frac{1}{1+\rho}\right)^{t} L_{t} U_{t}\left(C_{t} / L_{t}\right)\right]=\mathrm{E}_{0}\left[\sum_{t=0}^{\infty}\left(\frac{1}{1+\rho}\right)^{t} L_{t}\left[\frac{\left(C_{t} / L_{t}\right)^{1-1 / \eta}-1}{1-1 / \eta}\right]\right], \quad \rho>0 .
$$

The elasticity of intertemporal substitution equals $\eta$. The ethics of climate policy depend on the weight given to future generations (and thus on how small $\rho$ is) and on how small intergenerational inequality aversion is or how difficult it is to substitute current for future consumption per head (how low $1 / \eta$ is). Optimal climate policy faces some constraints governing the global economy. First, output at time $t$, $Z\left(K_{t}, L_{t}, F_{t}, R_{t}\right)$, is produced using capital $K_{t}$, labor, $L_{t}$, fossil fuels (e.g., oil, natural gas and coal), $F_{t}$, and renewables (e.g., solar or wind energy), $R_{t}$. We allow for imperfect factor substitution, so both fossil fuel and renewable energy are essential in production. Fossil fuel extraction costs, $G\left(S_{t}\right) F_{t}$, 
rise as reserves, $S_{t}$, fall, $G^{\prime}<0$. Renewable energy is supplied infinitely elastically at exogenously decreasing cost, $b_{t}$. Technical progress increases productivity in both aggregate and renewable energy production. Climate damages curb output and are captured by the factor $1-\Lambda\left(T_{t}\right), \Lambda^{\prime}<0$. Production net of costs of energy production and climate damage is allocated to consumption $C_{t}$, investments in manmade capital and depreciation with $\delta$ the rate of depreciation:

$$
K_{t+1}=(1-\delta) K_{t}+\Lambda\left(T_{t}\right) Z\left(K_{t}, L_{t}, F_{t}, R_{t}\right)-G\left(S_{t}\right) F_{t}-b_{t} R_{t}-C_{t} .
$$

The dynamics of fossil fuel reserves are:

$$
S_{t+1}=S_{t}-F_{t}=S_{0}-\sum_{s=0}^{t} F_{s}, \quad \sum_{t=0}^{\infty} F_{t} \leq S_{0}
$$

Golosov et al. (2014) introduce a two-stock carbon cycle where emissions lead to a permanent component $E_{1}$ and a transient component $E_{2}$ of the stock of carbon in the atmosphere:

$$
\begin{aligned}
& E_{1 t}=E_{1 t-1}+\varphi_{L} F_{t}, \\
& E_{2 t}=\varphi E_{2 t-1}+\varphi_{0}\left(1-\varphi_{L}\right) F_{t},
\end{aligned}
$$

where $\varphi_{L}$ denotes the fraction of emissions that stays permanently in the atmosphere, $\varphi$ the speed at which the temporary stock of carbon decays, and $\varphi_{0}$ a coefficient to calibrate how much of carbon is returned to the surface of the oceans and earth within a decade. We define temperature, $T_{t}$, as deviations from pre-industrial temperature in degrees Celcius. The climate sensitivity, $\omega$, corresponds to the rise in temperature ensuing from a doubling of the total stock of carbon in the atmosphere, $E_{t}$ :

(6) $\quad T_{t}=\omega \ln \left(\frac{E_{t}}{\bar{E}}\right) / \ln (2), \quad E_{t} \equiv E_{1 t}+E_{2 t}$,

where $\bar{E}=596.4 \mathrm{GtC}$ is the IPCC figure for the pre-industrial stock of atmospheric carbon. Using (6) we redefine damages as $D\left(E_{t}\right) \equiv \Lambda\left(\omega \ln \left(\frac{E_{t}}{\bar{E}}\right) / \ln (2)\right)$. This formulation ignores lags between atmospheric carbon and global warming and the improvements that result from a three-stock carbon cycle, but with these features one still gets a linear formula for the SCC (Gerlagh and Liski, 2012). The social planner maximizes (1) subject to (2)-(6). The Lagrangian is defined as:

$$
\begin{aligned}
& L \equiv \sum_{t=0}^{\infty}(1+\rho)^{-t}\left[L_{t} U_{t}\left(C_{t} / L_{t}\right)-\lambda_{t}\left(K_{t+1}-(1-\delta) K_{t}-D\left(E_{t}\right) Z\left(K_{t}, L_{t}, F_{t}, R_{t}\right)+G\left(S_{t}\right) F_{t}+b_{t} R_{t}+C_{t}\right)\right] \\
& +\sum_{t=0}^{\infty}(1+\rho)^{-t}\left[v_{1, t}\left(E_{1, t+1}-E_{1, t}-\varphi_{L} F_{t}\right)+v_{2, t}\left(E_{2, t+1}-(1-\varphi) E_{2, t}-\varphi_{0}\left(1-\varphi_{L}\right) F_{t}\right)-\mu_{t}\left(S_{t+1}-S_{t}+F_{t}\right)\right],
\end{aligned}
$$

where $\lambda_{t}$ denotes the shadow value of capital, $v_{1 t}$ and $v_{2 t}$ the shadow disvalue of the permanent and transient stocks of atmospheric carbon, and $\mu_{t}$ the shadow value of in-situ fossil fuel. The efficiency conditions for a social optimum are (appendix A): 


$$
\frac{C_{t+1} / L_{t+1}}{C_{t} / L_{t}}=\left(\frac{1+r_{t+1}}{1+\rho}\right)^{\eta}, \quad r_{t+1} \equiv D\left(E_{t+1}\right) Z_{K_{t+1}}-\delta
$$

$$
D\left(E_{t}\right) Z_{F_{t}} \leq G\left(S_{t}\right)+s_{t}+\tau_{t}, \quad F_{t} \geq 0, \quad \text { c.s., }
$$

$$
D\left(E_{t}\right) Z_{R_{t}} \leq b_{t}, \quad R_{t} \geq 0, \quad \text { c.s., }
$$

$$
\begin{aligned}
& s_{t}=-\sum_{\varsigma=0}^{\infty}\left[G^{\prime}\left(S_{t+1+\varsigma}\right) F_{t+1+\varsigma} \Delta_{t+\varsigma}\right], \\
& \tau_{t}=-\sum_{\varsigma=0}^{\infty}\left[\left\{\varphi_{L}+\varphi_{0}\left(1-\varphi_{L}\right)(1-\varphi)^{\varsigma}\right\} \Delta_{t+\varsigma} D^{\prime}\left(E_{t+1+\varsigma}\right) Z\left(K_{t+1+\varsigma}, L_{t+1+\varsigma}, F_{t+1+\varsigma}, R_{t+1+\varsigma}\right)\right] .
\end{aligned}
$$

with compound discount factors $\Delta_{t+\varsigma} \equiv \prod_{\varsigma^{\prime}=0}^{\varsigma}\left(1+r_{t+1+\varsigma^{\prime}}\right)^{-1}, \varsigma \geq 0$.

Equation (7) is the Euler equation, where the positive effect of the return on capital $\left(r_{t+1}\right)$ on consumption growth is bigger if intertemporal substitution is easier (high $\eta$ ). If fossil fuel is used, equation (8) indicates that its marginal product should equal marginal extraction cost plus the scarcity rent, $s_{t} \equiv \mu_{t} / \lambda_{t}$, plus the SCC, $\tau_{t} \equiv\left[\varphi_{L} v_{1 t}+\varphi_{0}\left(1-\varphi_{L}\right) v_{2 t}\right] / \lambda_{t}$. If the marginal product of fossil fuel is below total marginal cost, it is not used. Equation (9) states the equivalent condition for renewable use. Equation (10) follows from the Hotelling rule and gives the scarcity rent of keeping an extra unit of fossil fuel unexploited as the present discounted value of all future reductions in fossil fuel extraction costs. Equation (11) defines the SCC as the present discounted value of all future marginal global warming damages from burning an additional unit of fossil fuel. ${ }^{1}$

The SCC is proportional to GDP if utility is logarithmic, $\delta=1, D\left(E_{t}\right)=e^{-\gamma\left(E_{t}-\bar{E}\right)}$ with $\gamma>0$ the climate damage parameter, Cobb-Douglas production function for capital, labor and energy, and extraction does not require capital inputs. This leads to what we will refer to as the simple rule:

$$
\tau_{t}=\gamma\left[\left(\frac{1+\rho}{\rho-n}\right) \varphi_{L}+\left(\frac{1+\rho}{1+\rho-\varphi(1+n)}\right) \varphi_{0}\left(1-\varphi_{L}\right)\right] G D P_{t}
$$

where $G D P_{t}=D\left(E_{t}\right) Z\left(K_{t}, L_{t}, F_{t}, R_{t}\right)$ (Golosov et al., 2014), because the ratios of the future capital stock and aggregate consumption to GDP are constant, namely $K_{t+1}=\left[\frac{\alpha(1+n)}{1+\rho}\right] G D P_{t}$ and $C_{t}=\left\{1-\left[\frac{\alpha(1+n)}{1+\rho}\right]\right\} G D P_{t}$ with $\alpha$ the share of capital in value added (appendix B).

\footnotetext{
${ }^{1}$ One unit of carbon released from burning fossil fuel affects the economy in two ways: the first part remains in the atmosphere for ever and the second part gradually decays over time at a rate corresponding to roughly 1/300 per year.
} 


\section{Policy Simulation and Optimization}

In this section we report simulation results. Compared to the GHKT model of Golosov et al (2014), our benchmark has a higher intergenerational inequality aversion $(1 / \eta=2)$, a much lower elasticity of factor substitution as suggested by Hassler et al. (2012), partial depreciation of physical capital, and more convex climate damages as suggested by Weitzman (2010). We also compare our results to that of the model presented in GHKT. In our simulations time runs from 2010 till 2600 and is measured in decades, $t=0,1, . ., 59$, so period 0 corresponds to 2010-2020, period 1 to 2020-2030, etc. ${ }^{2}$ In the sensitivity analysis of section 5 we show the effects of the specific assumptions of GHKT to the extended model: unitary coefficient of intergenerational inequality aversion, unit elasticity of factor substitution, and the marginal global damages used in Golosov et al. (2014). Appendices C and D give further details on the functional forms, benchmark parameters and computational implementation. In table 1 and figure 1 we report full simulation results for the following four cases: (i) the extended model of section 2 with the carbon tax set to the fully optimal SCC as given in (11), (ii) the extended model with the carbon tax set to the sub-optimal simple rule (11'); (iii) the extended model with the carbon tax set to zero (i.e., no policy); and (iv) the model of GHKT (see end of section 2) with the carbon tax set to the SCC as given by the simple (and for the GHKT model optimal) rule (11'). We find that while the simple rule $\left(11^{\prime}\right.$

) is designed for the GHKT model, the rule captures most of the climate externality and brings welfare close to the first best even though many important assumptions for the rule's validity are not met.

Table 1: Transition times, welfare losses and carbon budget

\begin{tabular}{|c|c|c|c|c|c|c|}
\hline & $\begin{array}{c}\text { Fossil fuel } \\
\text { Only }\end{array}$ & $\begin{array}{c}\text { Simultaneous } \\
\text { use }\end{array}$ & $\begin{array}{c}\text { Renewable } \\
\text { Only }\end{array}$ & $\begin{array}{c}\text { Carbon } \\
\text { used }\end{array}$ & $\begin{array}{c}\text { Maximum } \\
\text { Temperature }\end{array}$ & $\begin{array}{c}\text { Welfare } \\
\text { loss }\end{array}$ \\
\hline $\begin{array}{c}\text { Optimum carbon tax in } \\
\text { general IAM }\end{array}$ & $2010-2050$ & $\mathrm{X}$ & $2060-$ & $710 \mathrm{GtC}$ & $2.4^{\circ} \mathrm{C}$ & 0 \\
\hline $\begin{array}{c}\text { Simple rule for carbon tax } \\
\text { in general IAM (11') }\end{array}$ & $2010-2060$ & $\mathrm{X}$ & $2070-$ & $950 \mathrm{GtC}$ & $2.8^{\circ} \mathrm{C}$ & $1 \%$ \\
\hline No policy in general IAM & $2010-2090$ & $\mathrm{X}$ & $2100-$ & $1820 \mathrm{GtC}$ & $4.0^{\circ} \mathrm{C}$ & $12 \%$ \\
\hline Optimum for GHKT IAM & $\mathrm{X}$ & $2010-$ & $\mathrm{X}$ & $4000 \mathrm{GtC}$ & $4.8^{\circ} \mathrm{C}$ & $\mathrm{n} / \mathrm{a}$ \\
\hline
\end{tabular}

Key: The welfare loss in the final column gives the percentage loss welfare relative to the first best, expressed as a percentage of initial consumption.

First-best fully optimal outcomes in the extended and GHKT IAM’s, (i) and (iv), correspond to the solid green and long-dashed blue lines in figure 1, respectively. The forecasts of transitional booms in productivity and population lead to sustained growth in consumption, output, and the capital stock over the next two centuries (as depicted in first, second and third panels in fig.1). In the extended IAM

\footnotetext{
${ }^{2}$ The final time period is $t=59$ or 2600-2610, but we focus on the transitional dynamics in the earlier parts of the simulation. Simulating the model of Golosov et al (2014) we extend the horizon by 1000 years till 3600 ( $\max t=159$ ) due to the transitional dynamics' strong dependence on terminal conditions, most notably asymptotic in situ depletion $\lim _{\varsigma \rightarrow \infty} S_{\varsigma}=0$.
} 
Consumption (per capita), $C_{t} / L_{t}$

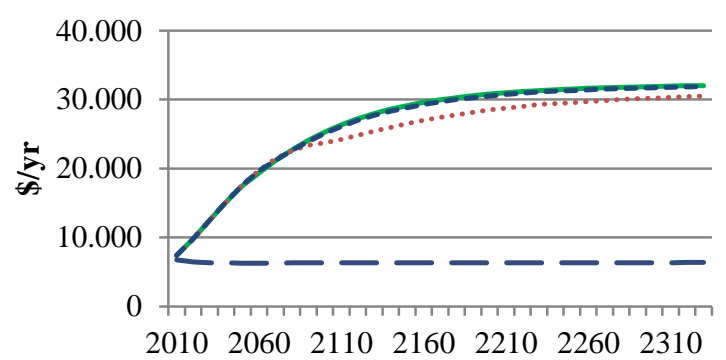

Capital Stock, $\mathbf{K}_{\mathbf{t}}$

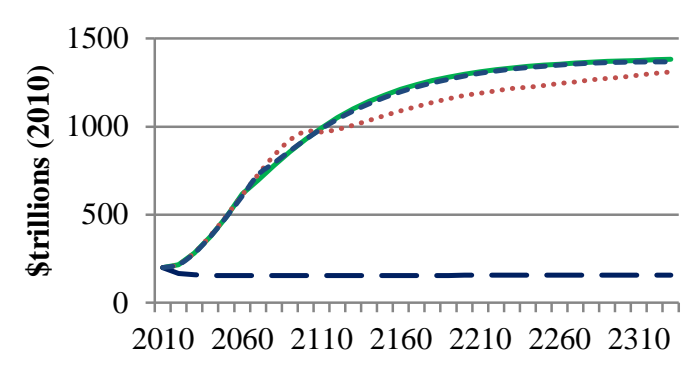

Fossil Fuel Use, Ft

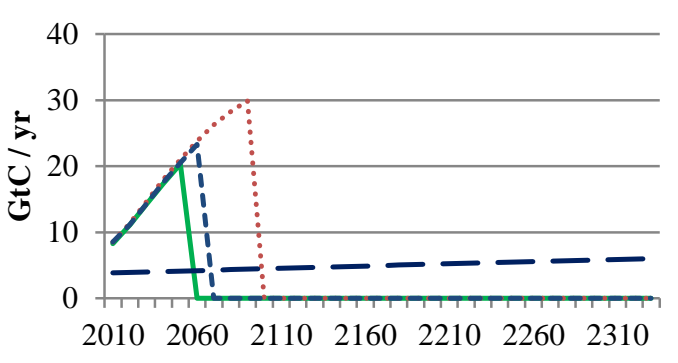

Carbon Tax, $\tau_{t}$

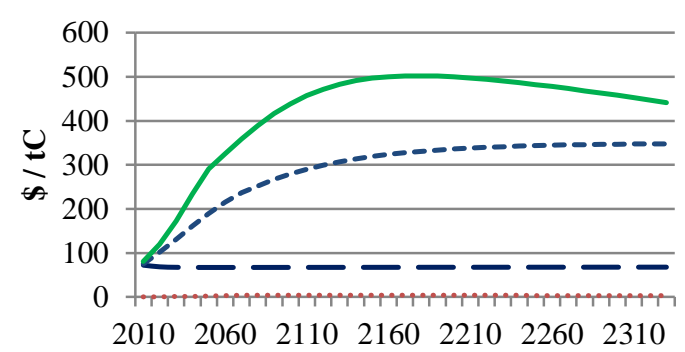

Fossil Reserves, $\mathrm{S}_{\mathrm{t}}$

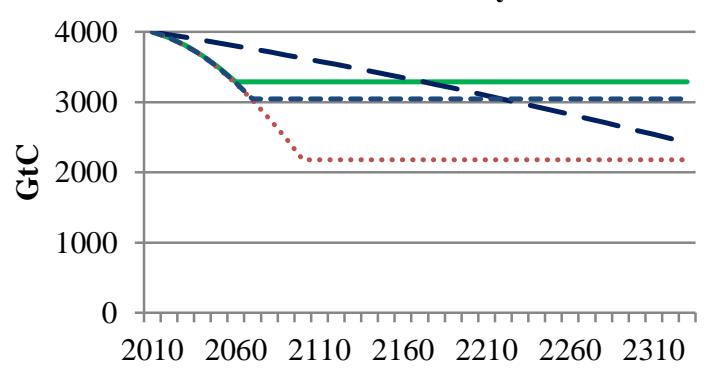

Output after Damage, $\mathrm{Z}_{\mathbf{t}}$

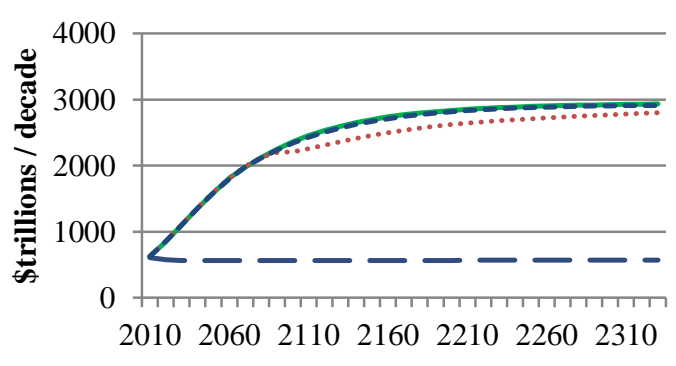

Mean Global Temperature, $T_{t}$

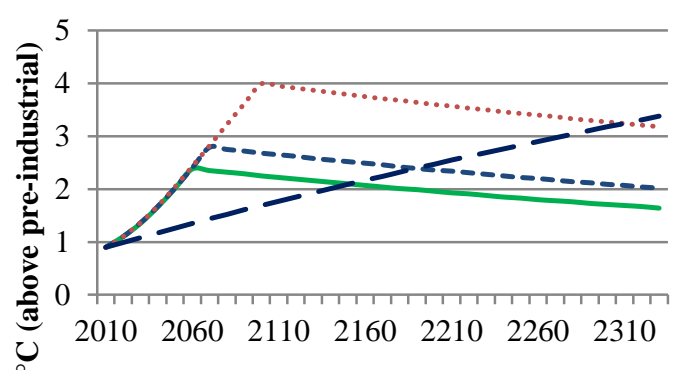

Renewable Energy Use, $\mathbf{R}_{t}$

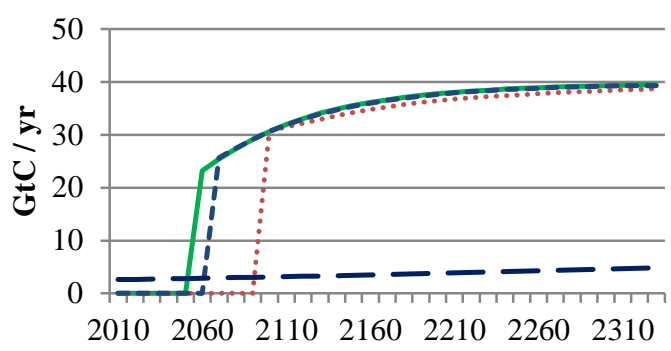

Hotelling Rent, $s_{t}$

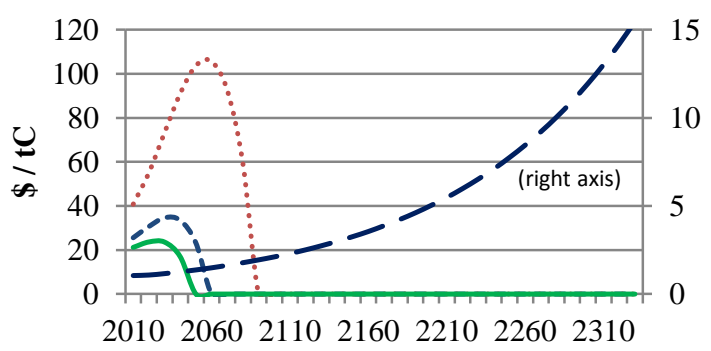

Key: Social optimum in general IAM ( $\square$ );

No policy (............);

Simple rule for the SCC (11') (- - - );

Social optimum in GHKT IAM ( -- );

Figure 1: Simulations of social optimum and business as usual in extended and GHKT IAM 
of section 2 the social optimum involves a period of initial fossil fuel use which is phased out halfway this century. After this switch point, energy is supplied from renewable sources. Optimal climate policy limits global warming to $2.4^{\circ} \mathrm{C}$ above pre-industrial temperature and is implemented through a rapidly rising carbon tax which flattens out and falls as economic growth and emissions taper off and decay of atmospheric carbon starts to dominate.

In contrast, the GHKT IAM features persistent simultaneous use of fossil and renewable energy sources. ${ }^{3}$ Under positive discounting, the fossil fuel extraction decreases by the discount factor but technical progress in both energy sectors sustains rising energy production. The absence of extraction costs implies asymptotic depletion of all in situ sources (4,000 GtC) and translates into high degrees of global warming of up to $4.8^{\circ} \mathrm{C}$ (which translate into a loss in output of mere $3.3 \%$ ). In contrast, in the general IAM of section 2 with extraction costs cumulative $710 \mathrm{GtC}$ are burnt and roughly 3,300 GtC is locked up in situ.

The no-policy scenario leads to inefficient allocation of resources with excessive fossil fuel extraction and high global warming damages. This lowers welfare by $12 \%$ of today's GDP, because it keeps consumption low in early periods of the program to allow for capital accumulation and consumption low in future periods due to high global warming of up to $4.0^{\circ} \mathrm{C}$. Without carbon taxation decarbonisation is delayed until the next century and cumulative emissions are two to three times that in the social optimum $(1,820 \mathrm{GtC})$.

\section{The optimal carbon tax is not proportional to GDP or aggregate consumption}

Figure 2 plots the ratio of the SCC to both GDP and aggregate consumption in the various scenarios. We observe that the SCC of the IAM of section 2 (solid green line) is not well described by a constant proportion of GDP or aggregate consumption. The general pattern of the SCC is a steeply rising section during the initial phases of fossil fuel use as more carbon emissions push up marginal climate damages whilst during the carbon-free phases the SCC falls as a proportion of GDP as a significant part of the stock of carbon in the atmosphere is gradually returned to the surface of the oceans and biomass. The transient population boom increases the initial slope as growth-related emission accelerates. The simple formula (11') performs even worse when expressed as a fraction of consumption, because the elasticity of substitution different from unity markedly shifts the consumption profile: the short-dashed blue and solid lines in panel (ii) have different levels and slopes. The short-dashed blue dashed lines in fig. 1 correspond to scenario (iv) and uses the simple GHKT rule for the carbon tax (11') in the IAM of section 2. While the carbon tax is rising too slowly compared to the SCC, the approximation is able to internalize the climate externality sufficiently to

\footnotetext{
${ }^{3}$ The absence of extraction costs in the model of Golosov et al. (2014) required us to keep their assumption of limited (unit) substitutability between fossil and renewable energy sources. Infinite elasticity would imply an unrealistically high initial extraction level and rapid extraction path.
} 
limit global warming to $2.8^{\circ} \mathrm{C}$ and curb the amount of carbon burnt to $910 \mathrm{GtC}$. The policy error in using a proportional policy rule is small, since the welfare loss relative to the first best is less than $1 \%$ of today’s GDP compared with 12\% under "laissez faire”.

(i) SCC/Output

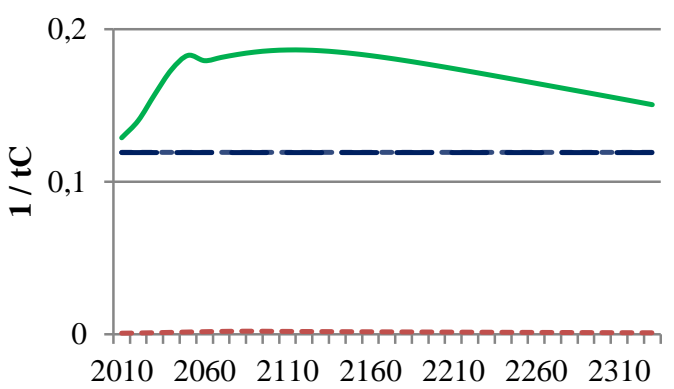

(ii) SCC/Consumption

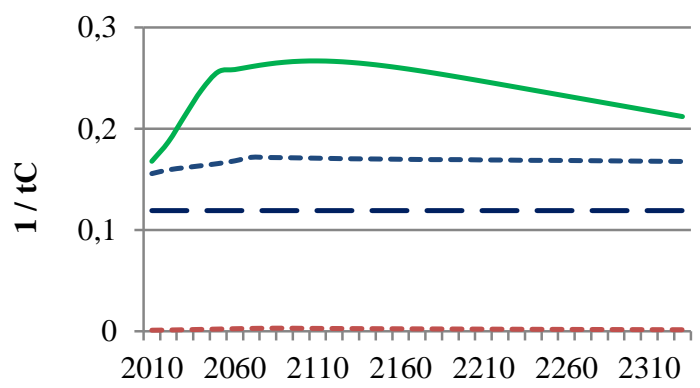

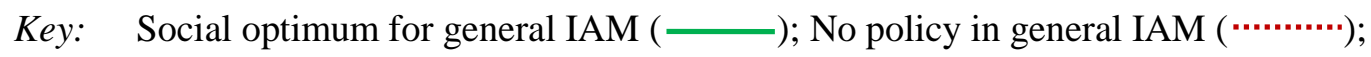

Simple rule (11') in general IAM ( - - - ); Social optimum for GHKT IAM ( — — );

Figure 2: The social cost of carbon as ratio of GDP and aggregate consumption

\section{Sensitivity with respect to the GHKT assumptions}

Figure 3 reports some robustness results to examine how the GHKT assumptions affect our benchmark results discussed in sections 3 and 4. i.e., logarithmic utility, and exponential damages.

First, a higher elasticity of substitution between energy and the capital-labor aggregate, $\vartheta=1>0.1$, as in the Cobb-Douglas specification of the GHKT IAM, makes energy demand more sensitive to change in relative cost of energy. This implies that the economy uses less energy and leaves more fossil fuel in situ which slightly lowers the social cost of carbon. It also allows an earlier transition to renewable energy, slightly lowering climate damages and the SCC. The simple rule (11') thus seems to function very well for different elasticities of factor substitution.

Second, a higher elasticity of intertemporal substitution, $\eta=1>0.5$, as in the logarithmic utility specification of the GHKT IAM corresponds to a lower coefficient of intergenerational inequality aversion (which was set to 2 in the baseline scenario), which implies that the SCC hurts earlier generations much more than later generations. Since the economy is growing, the social planner is relatively more concerned with fighting global warming than with avoiding big differences in consumption of different generations. The initial social cost of carbon increases.

Third, the optimal carbon tax under the prominent damage specification of DICE-2007 (Nordhaus, 2008) is virtually identical to the baseline trajectory as the two damage formulations differ by at most 0.1 percentage points on the relevant temperature range $\left(>2.5^{\circ} \mathrm{C}\right.$ above pre-industrial average). The slightly less convex damages relative to baseline imply a lower initial carbon tax and higher extraction rates which feed into higher carbon taxes in the long-run. 
Fourth, Golosov (2014) also give an expected marginal damage specification to capture the probability of catastrophic damages. ${ }^{4}$ Since this corresponds to a lower damage parameter, the resulting social cost of carbon is lower under this specification and becomes less responsive to changes in temperature.

Robustness - Social Cost of Carbon

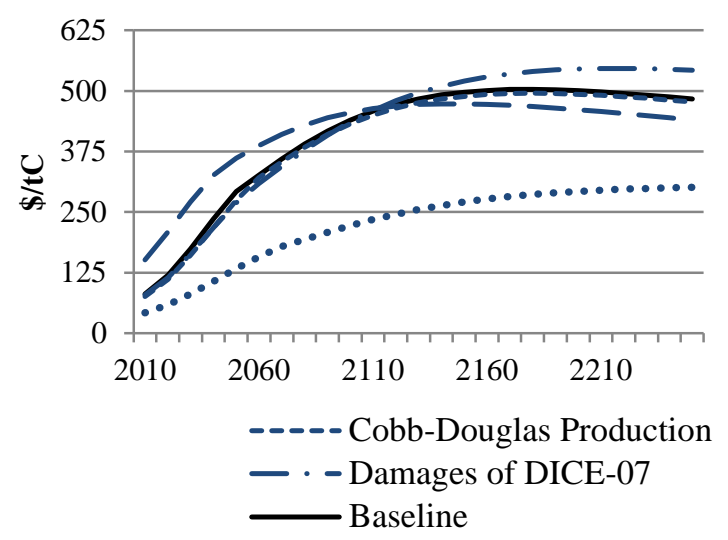

Robustness - SCC / C ratio

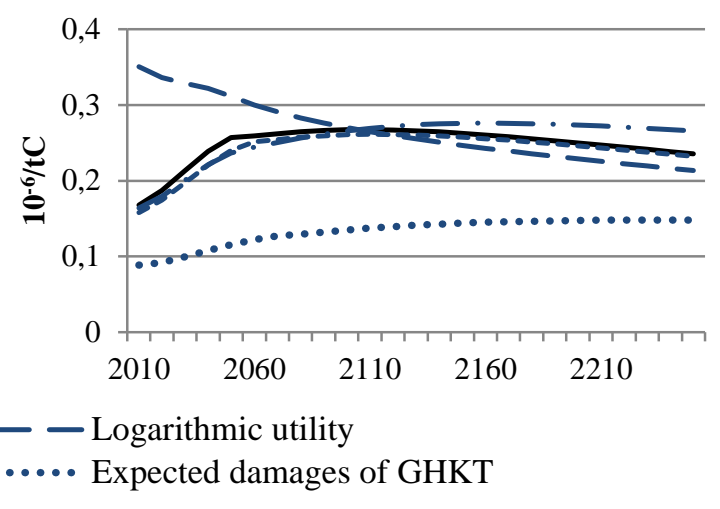

Figure 3: Sensitivity analysis for the social cost of carbon and the SCC/Consumption ratio

In general, the SCC rises steeply during the fossil fuel era, leveling off after the transition to carbonfree energy and declining only as atmospheric carbon levels recede due to dissipation and per-capita consumption levels stabilize. The right panel in figure 2 shows that these dynamics imply a non-linear relationship between the optimized consumption and carbon tax trajectories. This suggests that setting the carbon tax according to the simple rule (11') does not capture the general dynamics underlying the economy-environment nexus. Appendix D discusses the sensitivity results in more detail.

\section{Conclusion}

The optimal SCC is not well described by a constant proportion of GDP or aggregate consumption. In general, the SCC rises steeply during the initial phases of fossil fuel use as more carbon emissions push up marginal damages of global warming whilst during the carbon-free phases it falls as a proportion of GDP due to decay of the transient part of atmospheric carbon. This pattern is consistent over a broad range of key parameters. Although the simple rule for the optimal SCC put forward by Golosov et al. (2014) rises too slowly, the approximation internalizes the climate externality sufficiently to limit global warming to $2.8^{\circ} \mathrm{C}$ and reduce the amount of carbon burnt to $950 \mathrm{GtC}$. The policy error in using the simple formula for the SCC is small: the welfare loss relative to the first best is only $1 \%$ of today's GDP compared to a loss of $12 \%$ of today’s GDP under business as usual. The

\footnotetext{
${ }^{4}$ Golosov et al. demonstrate in their figure 1 that their reduced exponential damage function matches the damage specification of Nordhaus (2008) well for an exponential damage parameter $\gamma^{D I C E}=5.310^{-5}$. They proceed with uncertainty in future damages. With the probability of high damages, $p$, the ex ante expected damage parameter $\mathrm{E}[\gamma]=p \gamma^{\text {High }}+(1-p) \gamma^{\text {Low }}=0.932 \times 2.04610^{-4}+0.068 \times 1.06010^{-5}=2.37910^{-5}$, where GHKT calibrate $\gamma$ to a $93.2 \%$ probability of a loss of $0.48 \%$ of world GDP at 3 degrees Celsius and a $6.8 \%$ probability of a catastrophic loss of $30 \%$ of world GDP with 6 degrees Celsius (see page 67f.). In the simulations discussed in sections 3 and 4 we used $\gamma=5.310^{-5}$ as this corresponds closest to the deterministic damages of the DICE-2007 model.
} 
simple rule curbs global warming from $4{ }^{\circ} \mathrm{C}$ under business as usual to $2.8^{\circ} \mathrm{C}$, which is not far from the first best which curbs temperature to $2.4^{\circ} \mathrm{C}$. Although the simple rule induces sub-optimal energy transition times and amounts of untapped fossil fuel, we conclude that the simple rule avoids the most deleterious damages and is thus a lot better than doing nothing and performs in many respects well also in environments for which it was not designed.

\section{References}

Ackerman, F., Stanton, E., 2012. Climate risks and carbon prices: revising the social cost of carbon. Economics, The Open-Access, Open-Assessment E-Journal, 6, 2012-10.

Brock, W., Mirman, L., 1972. Optimal economic growth and uncertainty: the discounted case. Journal of Economic Theory, 4, 3, 479-513.

Gerlagh, R., Liski, M., 2012). Carbon prices for the next thousand years. CESifo Working Paper Series No. 3855. CESifo, Munich.

Iverson, T., 2013. Optimal carbon taxes with non-constant time preference. Mimeo., Colorado State University.

Golosov, M., Hassler, J., Krusell, P., Tsyvinski, A., 2014. Optimal taxes on fossil fuel in general equilibrium. Econometrica, 82, 1, 41-88.

Hassler, J., Krusell, P., 2012. Economics and climate change: integrated assessment in a multi-region world. Journal of the European Economic Association, 10(5), 974-1000.

Hassler, J., Krusell, P. and Olovsson, 2012. Energy-saving technical change, Working Paper 18456, NBER, Cambridge, Massachusetts.

IEA, 2008. World Energy Outlook 2008. http://www.iea.org/textbase/nppdf/free/2008/weo2008.pdf.

IPCC, 2007. Climate Change 2007, the Fourth IPCC Assessment Report.

\section{http://www.ipcc.ch/ipccreports/ar4-syr.htm}

McGlade, C., Ekins, P., 2015. The geographical distribution of fossil fuels unused when limiting global warming to 2 C, Nature, 517, 187-190.

Nordhaus, W., 2008. A Question of Balance: Economic Models of Climate Change. Yale University Press, New Haven, Connecticut.

Rezai, A., 2011. The opportunity cost of climate policy: a question of reference. Scandinavian Journal of Economics, 113, 885-903.

Rezai, A., van der Ploeg, F., 2013. Abandoning fossil fuel: how fast and how much? OxCarre Research Paper 123, University of Oxford.

Weitzman, M., 2010. What is the "damage function" for global warming- and what difference does it make? Climate Change Economics, 1, 57-69. 


\section{Appendix A: Necessary optimality conditions for the extended model}

Necessary conditions for a social optimum are:

(A.1) $\quad U^{\prime}\left(C_{t} / L_{t}\right)=\left(C_{t} / L_{t}\right)^{-1 / \eta}=\lambda_{t}$,

(A.2) $D\left(E_{t}\right) Z_{F_{t}} \leq G\left(S_{t}\right)+\left[\mu_{t}+\varphi_{L} v_{1 t}+\varphi_{0}\left(1-\varphi_{L}\right) v_{2 t}\right] / \lambda_{t}, \quad F_{t} \geq 0, \quad$ c.s.,

(A.3) $D\left(E_{t}\right) Z_{R_{t}} \leq b_{t}, \quad R_{t} \geq 0$, c.s.,

(A.4) $\quad\left(1-\delta+D\left(E_{t+1}\right) Z_{K_{t+1}}\right) \lambda_{t+1}=(1+\rho) \lambda_{t}$,

(A.5) $\mu_{t+1}=(1+\rho) \mu_{t}+G^{\prime}\left(S_{t+1}\right) F_{t+1} \lambda_{t+1}$,

(A.6) $\quad v_{1 t+1}=(1+\rho) v_{1 t}-D^{\prime}\left(E_{t+1}\right) Z_{t+1} \lambda_{t+1}$,

(A.7) $(1-\varphi) v_{2 t+1}=(1+\rho) v_{2 t}-D^{\prime}\left(E_{t+1}\right) Z\left(K_{t+1}, L_{t+1}, F_{t+1}, R_{t+1}\right) \lambda_{t+1}$.

Equations (A.1) and (A.4) give (7) and equations (A.2) and (A.3) yield (8) and (9) with $s_{t} \equiv \mu_{t} / \lambda_{t}$ and $\tau_{t} \equiv\left[\varphi_{L} v_{1 t}+\varphi_{0}\left(1-\varphi_{L}\right) v_{2 t}\right] / \lambda_{t}$. Equations (A.4) and (A.5) give (10). Finally, using (A.6), (A.7) and (A.4), the SCC, defined in final good units, can be found to equal (11).

\section{Appendix B: Necessary optimality conditions for the GHKT model}

We use a version of Golosov et al. (2014) which conflates coal, oil and natural gas into one fossil fuel source, $F_{t}$. The SCC is derived assuming that $U\left(C_{t} / L_{t}\right)=\ln \left(C_{t} / L_{t}\right), \delta=1, D\left(E_{t}\right)=e^{-\gamma\left(E_{t}-\bar{E}\right)}$, $Z_{t}=A_{t} L_{0 t}{ }^{1-\alpha-v} K_{t}^{\alpha} H_{t}{ }^{2}$, and $H_{t}=\left(\kappa_{1} F_{t}^{\chi}+\kappa_{2} R_{t}^{\chi}\right)^{1 / \chi}$ with $\varepsilon \equiv 1 /(1-\chi)>0$ the elasticity of factor substitution. Only labor is needed to extract fossil fuel or produce renewable energy: $F_{t}=A_{F t} L_{F t}$ and $R_{t}=A_{R, t} L_{R, t}$. Labor is perfectly mobile between the final goods and energy sectors:

(B.1) $L_{t}=L_{0 t}+F_{t} / A_{F t}+R_{t} / A_{R t}$.

where $L_{t}$ denotes the exogenous aggregate supply of labor. The carbon cycle is still given by (3)-(5). After substitution of $L_{0 t}$ the Lagrangian function for this problem is:

$$
\begin{aligned}
L \equiv & \sum_{t=0}^{\infty}(1+\rho)^{-t}\left\{L_{t} \ln \left(C_{t} / L_{t}\right)-\mu_{t}\left(S_{t+1}-S_{t}+F_{t}\right)\right\} \\
& +\sum_{t=0}^{\infty}(1+\rho)^{-t}\left\{v_{1 t}\left[E_{1 t}-E_{1 t-1}-\varphi_{L} F_{t}\right]+v_{2 t}\left[E_{2 t}-\varphi E_{2 t-1}-\varphi_{0}\left(1-\varphi_{L}\right) F_{t}\right]\right\} \\
& -\sum_{t=0}^{\infty}(1+\rho)^{-t} \lambda_{t}\left\{K_{t+1}+C_{t}-e^{-\gamma\left(E_{1 t}+E_{2 t}-\bar{E}\right)} A_{0 t}\left(L_{t}-F_{t} / A_{F t}-R_{t} / A_{R t}\right)^{1-\alpha-v} K_{t}^{\alpha}\left[\left(\kappa_{1} F_{t}^{\chi}+\kappa_{2} R_{t}^{\chi}\right)^{1 / \chi}\right]^{\nu}\right\},
\end{aligned}
$$


Maximizing with respect to $C_{t}$ and $K_{t}$ yields $L_{t} / C_{t}=\lambda_{t}$ and $(1+\rho) \lambda_{t-1}=\alpha \lambda_{t} Y_{t} / K_{t}$ which gives $\frac{\alpha}{1+\rho} \frac{C_{t-1}}{L_{t-1}}=\frac{K_{t}}{Y_{t}} \frac{C_{t}}{L_{t}}$, where $Y_{t} \equiv D\left(E_{t}\right) Z_{t}$. It follows that $\frac{\alpha}{1+\rho} \frac{L_{t}}{L_{t-1}} \frac{C_{t-1}}{Y_{t-1}}=\left(1-\frac{C_{t-1}}{Y_{t-1}}\right) \frac{C_{t}}{Y_{t}}$. Assuming constant population growth $n$, i.e., $L_{t}=(1+n) L_{t-1}$, we have (cf. Brock and Mirman, 1972):

$$
K_{t+1}=\left[\frac{\alpha(1+n)}{1+\rho}\right] Y_{t}, \quad C_{t}=\left\{1-\left[\frac{\alpha(1+n)}{1+\rho}\right]\right\} Y_{t} .
$$

Maximizing with respect to the permanent and transient stocks of atmospheric carbon, we get $\gamma Y_{t} \lambda_{t}=\frac{\gamma L_{t}}{1-\alpha(1+\rho)^{-1}(1+n)}=v_{1 t}-\frac{v_{1 t+1}}{1+\rho}=v_{2 t}-\frac{\varphi v_{2 t+1}}{1+\rho}$, which gives:

(B.3a) $\quad v_{1 t}=\frac{\gamma L_{t}}{\left[1-(1+\rho)^{-1}(1+n)\right]\left[1-\alpha(1+\rho)^{-1}(1+n)\right]}$, and

$$
v_{2 t}=\frac{\gamma L_{t}}{\left[1-\varphi(1+\rho)^{-1}(1+n)\right]\left[1-\alpha(1+\rho)^{-1}(1+n)\right]}
$$

Making use of (B.2) and (B.3a) and (B3b) we get the SCC, $\tau_{t} \equiv\left[\varphi_{L} v_{1 t}+\varphi_{0}\left(1-\varphi_{L}\right) v_{2 t}\right] / \lambda_{t}$ as (11'). The SCC is thus proportional to world GDP (usual output after damage). The SCC as fraction of GDP is higher if society is more patient (lower $\rho$ ), damages are more sensitive to the stock of atmospheric carbon (higher $\gamma$ ), the temporary component of atmospheric carbon decays more quickly (higher $\varphi$ ), and population growth is bigger. If all carbon stays in the atmosphere forever $(\varphi=1)$, equation (11') simplifies to $\tau_{t}=\left(\frac{1+\rho}{\rho-n}\right) \varphi_{L}^{*} \gamma Y_{t}$, where $\varphi_{L}^{*} \equiv \varphi_{L}+\varphi_{0}\left(1-\varphi_{L}\right)$. Since global warming is the only market failure, the social optimum can be realized in a market economy by setting the optimal carbon tax exactly equal to the SCC and refunding the revenues in a lump-sum fashion to the private sector.

Maximizing with respect to $F_{t}$, and $R_{t}$ yields $A_{R t} v \frac{Y_{t}}{H_{t}} \kappa_{R}\left(\frac{H_{t}}{F_{R t}}\right)^{1-\chi} \lambda_{t}=w_{t} \lambda_{t}$,

$v \frac{Y_{t}}{H_{t}} \kappa_{1}\left(\frac{H_{t}}{F_{t}}\right)^{1-\chi} \lambda_{t}=\mu_{t}+\eta_{t}+\frac{w_{t}}{A_{1 t}} \lambda_{t}$ or alternatively:

$$
v \frac{Y_{t}}{H_{t}} \kappa_{1}\left(\frac{H_{t}}{F_{t}}\right)^{1-\chi}=\frac{w_{t}}{A_{F t}}+s_{t}+\tau_{t}, \quad v \frac{Y_{t}}{H_{t}} \kappa_{2}\left(\frac{H_{t}}{F_{R t}}\right)^{1-\chi}=\frac{w_{t}}{A_{R t}},
$$

where the wage is $w_{t}=(1-\alpha-v) \frac{Y_{t}}{L_{0 t}}$ and the scarcity rent of oil is $s_{t} \equiv \mu_{t} / \lambda_{t}$. The first part of (B.4) states that the marginal product of oil is set to the sum of the labor cost involved in extracting oil, the scarcity rent of oil and the social cost of carbon. The second part of (B.4) states that the marginal 
product of renewable energy equals the labor cost of producing it. The labor cost is less if efficiency of labor is higher and if the wage is less. Equations (B.4) can be solved for the two types of energy use (labor use in fossil and renewable production), aggregate energy use and world GDP as functions of the scarcity rent of oil, the social cost of carbon, the capital stock and the total stock of atmospheric carbon given aggregate labor supply and the technology parameters.

Maximizing with respect to $S_{t}$ gives $(1+\rho) \mu_{t-1}=\mu_{t}$ and the Hotelling rule:

(B.5) $s_{t}=\frac{\alpha Y_{t}}{K_{t}} s_{t-1}$.

This rule states that the scarcity rent of oil should grow at the rate of interest for society to be indifferent between keeping an extra barrel of oil in the ground and extracting an extra barrel of oil. Since extraction costs of fossil fuel do not become infinitely large as oil and gas reserves vanish, the optimum is characterized by asymptotic depletion of these reserves.

The no-policy outcome does not internalize climate externalities and thus corresponds to a zero carbon tax, $\tau_{t}=0$. It follows from (B.4) and (B.5) that $s_{t}=v \frac{Y_{t}}{H_{t}} \kappa_{1}\left(\frac{H_{t}}{F_{t}}\right)^{1-\chi}-\frac{w_{t}}{A_{R t}}=\frac{\alpha Y_{t}}{K_{t}} s_{t-1}$. Abstracting from extraction costs of oil and gas $\left(A_{F t} \rightarrow \infty\right)$, supposing a Cobb-Douglas production for the energy aggregate $(\chi \rightarrow 0)$, abstracting from technological progress in renewable energy production $\left(A_{R t} \rightarrow\right.$ $\left.A_{R}\right)$, we get $F_{t}=(1+\rho)^{-1}(1+n) F_{t-1}$. Imposing the condition that asymptotically in situ reserves are depleted, we obtain $F_{t}=\left[1-\left(\frac{1+n}{1+\rho}\right)\right] S_{t}=\left(\frac{\rho-n}{1+\rho}\right)\left(\frac{1+n}{1+\rho}\right)^{t} S_{0}$, so that extraction of oil and gas occurs more rapidly if the discount rate is high and population growth is small. For any given current rate of oil extraction the rate of future oil extraction is higher in the social optimum than under "laissez faire". Hence, the former postpones oil extraction and carbon emissions compared to "laissez faire", especially if carbon decay is slow and society is patient (small $\varphi$, low $\rho$ ).

\section{Appendix C: Functional forms and calibration}

In the simulations we use iso-elastic utility function $U(C / L)=\frac{(C / L)^{1-1 / \eta}-1}{1-1 / \eta}$. We set the elasticity of intertemporal substitution to $\eta=1 / 2$ and thus intergenerational inequality aversion to 2 . In the sensitivity section we also present results for logarithmic utility. The pure rate of time preference $\rho$ is set to $10 \%$ per decade which corresponds to $0.96 \%$ per year.

We employ an extraction technology of the form $G(S)=\gamma_{1}\left(S_{0} / S\right)^{\gamma_{2}}$, where $\gamma_{1}$ and $\gamma_{2}$ are positive constants. This specification implies that reserves will not be fully be extracted; some fossil fuel 
remains untapped in the crust of the earth. Extraction costs are calibrated to give an initial share of energy in GDP between 5\%-7\% depending on the policy scenario. This translates to fossil production costs of \$350/tC (\$35/barrel of oil), where we take one barrel of oil to be equivalent to $1 / 10$ ton of carbon. This gives approximately $G\left(S_{0}\right)=\gamma_{1}=0.75$. The IEA (2008) long-term cost curve for oil extraction gives a doubling to quadrupling of the extraction cost of oil if another $1000 \mathrm{GtC}$ are extracted. Since we are considering all carbon-based energy sources (not only oil) which are more abundant and cheaper to extract, we assume a more doubling but less than quadrupling of production costs if a total $3000 \mathrm{GtC}$ is extracted. With $S_{0}=4000 \mathrm{GtC}$, ${ }^{5}$ this gives $\gamma_{2}=0.75 .{ }^{6}$ In general, we assume very low extraction costs and a high initial stock of reserves.

The unit cost of renewable energy is calibrated to the percentage of GDP necessary to generate all energy demand from renewables. Under a Leontief technology, with $\vartheta \rightarrow 0$, energy demand is $\sigma Z_{t}$ with $Z_{t}$ potential, pre-damage output and $\sigma$ the carbon intensity of output. The cost of generating all energy carbon free is $\sigma Z_{t} b_{t} / Z_{t}=\sigma b_{t}$. Nordhaus (2008) assumes that it costs $5.6 \%$ of GDP to achieve this. We take double this number $\sigma b_{1}=0.12$ (i.e. we assume $12 \%$ ) or, with $\sigma=0.62$ as derived below, $b_{1}=2$. In the future this cost falls to current prices of fossil energy (with energy amounting to about $5 \%$ of GDP), that is $b_{t}$ approaches 0.8 ). We assume that exogenous technical progress lowers the unit cost at a falling rate starting at a reduction of $1 \%$ per year. Specifically, $b_{t}=0.8+1.2 e^{-0.1 t}$. This calibration is done for a Leontief technology. We assume that for a more general technology the same parameter values can be applied. Our calibration assumes that renewable energy is initially very expensive and falls to current levels only in the very long run. This, together with the assumption about fossil energy, biases the model against rapid de-carbonization.

The initial capital stock is set to 200 (US\$ trillion), which is taken from Rezai and van der Ploeg (2013). We set $\delta$ to be 0.5 per decade, which corresponds to a yearly depreciation rate of $6.7 \%$.

Population in $2010\left(L_{1}\right)$ is 6.5 billion people. Following Nordhaus (2008) and UN projections population growth is given by $L_{t}=8.6-2.1 e^{-0.35 t}$. Population growth starts at $1 \%$ per year and falls below $1 \%$ percent per decade within six decades and flattens out at 8.6 billion people. Without loss of generality the efficiency of labor $A_{t}^{L}=3-2 e^{-0.2 t}$ starts out with $A_{1}^{L}=1$ and an initial Harrod-neutral rate of technical progress of $2 \%$ per year. The efficiency of labor stabilizes at 3 times its current level.

\footnotetext{
${ }^{5}$ Stocks of carbon-based energy sources are notoriously hard to estimate. IPCC (2007) assumes in its A2scenario that $7000 \mathrm{GtCO}_{2}$ (with $3.66 \mathrm{tCO} 2$ per tC this equals $1912 \mathrm{GtC}$ ) will be burnt with a rising trend this century alone. We roughly double this number to get our estimate of $4000 \mathrm{GtC}$ for initial fossil fuel reserves. Nordhaus (2008) assumes an upper limit for carbon-based fuel of $6000 \mathrm{GtC}$ in the DICE-07.

${ }^{6}$ Since $G(1000) / G(4000)=(4000 / 1000)^{\gamma_{2}}=4^{\gamma_{2}}$ and $4^{0.75}=2.8$.
} 
Output before damages is $Z_{t}=\left[(1-\beta)\left(A K_{t}^{\alpha}\left(A_{t}^{L} L_{t}\right)^{1-\alpha}\right)^{1-1 / \vartheta}+\beta\left(\frac{F_{t}+R_{t}}{\sigma}\right)^{1-1 / \vartheta}\right]^{\frac{1}{1-1 / \vartheta}}, \vartheta \geq 0,0<\alpha<1$ and $0<\beta<1$. This is a constant-returns-to scale CES production function in energy and a capitallabor composite with $\vartheta$ the elasticity of substitution, $\beta$ the share the parameter for energy, and $\sigma$ the carbon intensity of output. The capital-labor composite is defined by a constant-returns-to-scale CobbDouglas function with $\alpha$ the share of capital, $A$ total factor productivity and $A_{t}^{L}$ the efficiency of labor. The two types of energy are perfect substitutes in production. Damages are calibrated so that they give the same climate damages for the initial levels of output and mean temperature. It is convenient to rewrite production before damages as $Z_{t}=Z_{0}\left[(1-\beta)\left(\frac{A K_{t}^{\alpha}\left(A_{t}^{L} L_{t}\right)^{1-\alpha}}{Z_{0}}\right)^{1-1 / \vartheta}+\beta\left(\frac{F_{t}+R_{t}}{\sigma Z_{0}}\right)^{1-1 / \vartheta}\right]^{\frac{1}{1-1 / \vartheta}}$. We set the share of capital to $\alpha=0.35$, the energy share parameter to $\beta=0.05$, and the elasticity of factor substitution to $\vartheta=0.1$ in accordance with recent finding in Hassler et al. (2010). In the sensitivity section we also present results for $\vartheta=1$.World GDP in 2010 is 63 \$trillion. The energy intensity of output $\sigma$ is calibrated to current energy use. In the Leontief case energy demand (only fossil fuel initially) is $F_{0}=\sigma D_{0} Z_{0}$. With carbon input equal to $8.36 \mathrm{GtC}$ in 2010 , we obtain $\sigma=(8.36 / 2.13) / 63=0.062$. Finally, given $A_{1}^{L}=1$ we can back out $A=34.67$.

Following Golosov et al. (2014), the decay rate for the transient stock of atmospheric carbon is $\varphi=0.0228$ and $\varphi_{L}=0.2$, so that $20 \%$ of carbon emissions stay up 'forever' in the atmosphere and the remainder has a mean life of about 300 years The parameter $\varphi_{0}=0.393$ is calibrated so that about half of the carbon impulse is removed after 30 years. We set $E_{0}^{P}=103 \mathrm{GtC}$ and $E_{0}^{T}=699 \mathrm{GtC}$. We suppose an equilibrium climate sensitivity of $\omega=3$.

Nordhaus (2008) supposes that with global warming of $2.5^{\circ} \mathrm{C}$ damages are $1.7 \%$ of world GDP and uses this to calibrate: $D\left(T_{t}\right)=\frac{1}{1+0.00284 T_{t}^{2}}=\frac{1}{1+\left(T_{t} / 18.8\right)^{2}}$. Weitzman (2010) argues that global warming damages rise more rapidly at higher levels of mean global temperature. With climate damages equal to $50 \%$ of world GDP at $6^{\circ} \mathrm{C}$ and $99 \%$ at $12.5^{\circ} \mathrm{C}$, Ackerman and Stanton (2012) calibrate $D\left(T_{t}\right)=\frac{1}{1+\left(T_{t} / 20.2\right)^{2}+\left(T_{t} / 6.08\right)^{6.76}}$. The extra term in the denominator captures potentially catastrophic losses at high temperatures. In the sensitivity section we also present results for the expected damage specification used in Golosov et al. (2014). 


\section{Appendix D: Computational implementation}

The transversality condition for the model is $\lim _{t \rightarrow \infty} e^{-\rho t}\left(\lambda_{t} K_{t}+\mu_{t} S_{t}+\eta_{1 t} E_{t}^{P}+\eta_{2 t} E_{t}^{T}\right)=0$. In our simulations we solve the model for finite time and use the turnpike property to approximate the infinite-horizon problem. All equilibrium paths approach the steady state quickly such that the turnpike property renders terminal conditions essentially unimportant. We allow for continuation stocks to reduce the impact of the terminal condition on the transitions paths in the early periods of the program. We use the computer program GAMS and its optimization solver CONOPT3 to solve the model numerically. The social planner optimum in which the externality is taken into account fit the program structure readily. To solve for the "laissez faire" equilibrium paths, we adopt the iterative approach discussed in detail in Rezai (2011). Briefly, to approximate the externality scenario, the aggregate economy is fragmented into $N$ dynasties. Each dynasty has $1 / N$ th of the initial endowments and chooses consumption, investment and energy use in order to maximize the discounted total utility of per capita consumption. The dynasties understand the contribution of their own emissions to the climate change, but take carbon emissions of others as given. The climate dynamics are affected by the decisions of all dynasties. This constitutes the market failure.

It might seem easier to simply assume that there is one dynasty that ignores the externality but this would not be a rational expectations equilibrium. The externality problem is not an optimization but an equilibrium problem. The CONOPT3 solver of GAMS is powerful in solving maximization problems and it is more efficient to adopt an iterative routine in which a planner of a fragmented economy solves an optimization problem representatively than to attempt solving the equilibrium conditions directly. Given our specifications, the computation of the equilibrium problem takes less than one minute. To introduce this approximate externality, we make the following adjustments to the initial stocks $K(0)=K_{0} / N, S(0)=S_{0} / N$ and $L(0)=L_{0} / N$. All production and cost functions are homogeneous of degree 1 and therefore invariant to $N$. The introduction of the pollution externality only requires a modification of the transition equation of atmospheric carbon to include emissions regarded as exogenous by each dynasty:

$$
\begin{aligned}
& E_{1 t}=E_{1 t-1}+\varphi_{L}\left(F_{t}+F_{t}^{e x g}\right), \\
& E_{2 t}=\varphi E_{2 t-1}+\varphi_{0}\left(1-\varphi_{L}\right)\left(F_{t}+F_{t}^{e x g}\right) .
\end{aligned}
$$

Under "laissez faire" dynasties essentially play a dynamic non-cooperative game, which leads to a Nash equilibrium in which each agent forecasts the paths of emissions correctly and all agents take the same decisions as all dynasties are identical. Equilibrium requires $F_{t}^{\text {exg }}=(N-1) F_{t}$. Under "laissez faire” the planner only adjusts her controls to take into account the effects of her own decisions (i.e. $1 / N$ th of the climate externality). If $N=1$ the externality is internalized and we obtain the social optimum. As $N \rightarrow \infty$, we obtain the "laissez faire" outcome characterized in section 2. 
Following Rezai (2011), the numerical routine starts by assuming a time path of emissions exogenous to the dynasty's optimization, $F_{t}^{e x g}$, at an informed guess. GAMS solves for the representative dynasty's welfare-maximizing investment, consumption, and energy use choices conditional on this level of exogenous emissions. $(N-1)$ times the dynasty's emission trajectory, $F_{t}$, defines the time profile of exogenous emissions in the next iteration, $F_{t}^{e x g}{ }^{\prime}$. The routine is repeated and $F_{t}^{\text {exg }}$ updated until the difference in the time profile between iterations meets a pre-defined stopping criterion. In the reported results iterations stop if the deviation $\left|(N-1) F_{t} / F_{t}^{e x g}-1\right|$ in each time period is at most $0.001 \%$.

We set $N=400$ to account for the fact that in the present world economy, the externality in the market of GHG emissions is already internalized to a very small extent through the imposition of carbon taxes or tradable emission permits and non-market regulation (e.g. through the Kyoto Protocol or the establishment of the European Union Emission Trading Scheme). In our "laissez faire" simulations, the dynastic planner takes into account less than $0.25 \%$ of global emissions. 